\title{
EXPERIMENTAL EXAMINATION OF PERFORMANCE CONSEQUENCES OF CHANGE IMPLEMENTATION FOR SALES FORCE INTEGRATION
}

\author{
Joon-Hee Oh, Georgia State University, USA
}

\begin{abstract}
This study designs and conducts a laboratory experiment that replicates the experimental study of Weber and Camerer (2003). In the replication, however, this study includes a more realistic aspect of real-world strategic changes, the different employee cultural compositions within the post-change groups. The findings confirm that cultural conflicts are one of the major reasons for post-change performance deterioration. This study also finds that cultural dominance is present in the postchange group and affects the post-change performance when the group includes a different composition of salespersons from the pre-change groups. The managerial implications are provided to help build a strategy for successful strategic changes to manage the post-change integration process, because dominating post-change group structures are common in the real world. This study also investigates the learning process within the experimental setting and finds that the development of collaborative learning contributes to competitive knowledge development, which in turn contributes to organizational performance.
\end{abstract}

References available upon request 